\title{
Lower genital tract infections in young female juvenile idiopathic arthritis patients
}

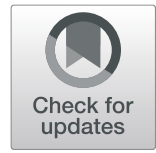

\author{
Gabriela R. V. Ferreira ${ }^{1 \dagger}$, Renato B. Tomioka ${ }^{2,3 \dagger}$, Ligia B. Queiroz ${ }^{4}$, Katia Kozu', Nadia E. Aikawa 1,3, \\ Adriana M. E. Sallum ${ }^{1}$, Paulo Serafini ${ }^{2}$, Maricy Tacla ${ }^{2}$, Edmund C. Baracat ${ }^{2}$, Rosa M. R. Pereira ${ }^{3}$, Eloisa Bonfá ${ }^{3}$ and \\ Clovis A. Silva ${ }^{1,3^{*}}$ (D)
}

\begin{abstract}
Background: To evaluate human papillomavirus (HPV), Chlamydia trachomatis (CT) and Neisseria gonorrhoeae (NG) infections in juvenile idiopathic arthritis (JIA) patients.

Methods: After exclusion, 33 female adolescent and young JIA patients (ILAR criteria) and 28 healthy controls were selected for this study. Demographic data, gynecological, sexual function, cervical cytology and histological abnormalities were evaluated. JIA clinical/laboratorial parameters and treatment were also assessed. HPV-DNA, CTDNA and NG-DNA testing in cervical specimens were performed by Hybrid Capture 2 assays.

Results: The mean current age was similar in JIA patients and controls ( $23.3 \pm 6.24$ Vs. $26.1 \pm 6.03$ years, $p=0.09)$. The frequencies of sexual intercourse ( $76 \%$ vs. $89 \%, p=0.201)$ and abnormal cervical cytology ( $24 \% \mathrm{vs} .11 \%, p=$ 0.201) were similar in JIA compared to controls. The higher frequency of HPV infection in JIA patients than controls ( $30 \%$ vs. $11 \%, p=0.155)$ did not reach statistical significance. CT ( $0 \%$ vs. $7 \%, p=0.207)$ and NG infections ( $0 \%$ vs. $4 \%, p=0.459$ ) were also alike in both groups. Further evaluation of JIA patients with abnormal and normal cervical cytology showed that the former group had a higher frequency of HPV infection ( $87 \%$ vs. $12 \%, p=0.0002)$ with a low frequency of HPV vaccination ( $0 \%$ vs. $8 \%, p=1.0)$. No differences were evidenced between these two JIA groups regarding demographic data, sexual function and clinical/laboratorial parameters. The frequencies of methotrexate $(p=0.206)$ and biological agent use $(p=0.238)$ were similar in both JIA groups.

Conclusions: To our knowledge, this was the first study to assess lower genital infections in JIA patients allowing the identification of HPV as main cause of cervical dysplasia. Methotrexate and biological agents do not seem to increase risk of lower genital tract infections in JIA patients.
\end{abstract}

Keywords: Human papillomavirus, Chlamydia trachomatis, Neisseria gonorrhoeae, Infection, Juvenile idiopathic arthritis

\section{Introduction}

Juvenile idiopathic arthritis (JIA) includes a heterogeneous group of diseases characterized by chronic arthritis [1-3]. This painful and disable disease occurs mainly in females during the adolescence and young adulthood. Patients

\footnotetext{
*Correspondence: clovis.silva@hc.fm.usp.br; clovisa.silva@hc.fm.usp.br ${ }^{\dagger}$ Gabriela R. V. Ferreira and Renato B. Tomioka contributed equally to this work.

'Pediatric Rheumatology Unit, Children's Institute, Hospital das Clinicas HCFMUSP, Faculdade de Medicina, Universidade de Sao Paulo, Av. Dr. Eneas Carvalho Aguiar, 647 - Cerqueira César, São Paulo, SP 05403-000, Brazil ${ }^{3}$ Rheumatology Division, Hospital das Clinicas HCFMUSP, Faculdade de Medicina, Universidade de Sao Paulo, Av. Dr. Eneas Carvalho Aguiar, 647 Cerqueira César, São Paulo, SP 05403-000, Brazil

Full list of author information is available at the end of the article
}

may have a precocious sexual activity with a possibility of sexually transmitted infections (STI) [4].

Others and we have previously demonstrated that lower genital tract infections, such as human papillomavirus (HPV) and Chlamydia trachomatis (CT) [5-8] are relevant issues in sexually active adults with rheumatoid arthritis (RA). There are, however, no studies assessing these infections and Neisseria gonorrhoeae (NG) in female adolescent and young adults with JIA.

Therefore, the objective of the present study was to evaluate these STI infections in JIA patients. The possible associations among these infections with demographic

(c) The Author(s). 2019 Open Access This article is distributed under the terms of the Creative Commons Attribution 4.0 International License (http://creativecommons.org/licenses/by/4.0/), which permits unrestricted use, distribution, and 
data, sexual function, disease parameters and treatment were also analyzed.

\section{Methods}

A cross-section study was conducted from September 2014 to June 2016 and all 110 female JIA patients, aged between 15 and 40 years, were invited. JIA patients fulfilled the International League of Associations for Rheumatology (ILAR) classification criteria [9] and were followed at two services: Pediatric Rheumatology Unit and Rheumatology Division of our tertiary university hospital.

The exclusion criteria were other chronic diseases $(n=10)$, current gestation or lactation $(n=3)$ and refusal to participate in this study $(n=64)$. Thus, after the exclusion of 77 patients, 33 post-pubertal JIA patients were studied. The healthy age-matched control group included 28 community post-pubertal females adolescents or young adults, between 15 and 40 years of age, selected consecutively using the same exclusion criteria. The Local Ethics Committee of our tertiary service approved the study and an informed consent was obtained from all participants or their legal guardian. Treatments in JIA patients with abnormal and normal cervical cytology were included in Table 1.

\section{Demographic data}

The demographic data included current age, disease duration and ethnicity. Socioeconomic class according to Brazilian classification were divided in five categories: upper, upper-middle, middle, lower-middle and lower socioeconomic classes [10].

\section{Sexual function and gynecological evaluation}

The presence of vaginal discharge and sexual function (age of first sexual intercourse, number of sexual activity in the last month, number of sexual activity in the last year, number of sexual partners in the last month and number of sexual partners in the last year) were registered based on recollection [6]. A systematic clinical examination of the genitalia was performed by the same expert gynecologist at study entry and includes evaluation of vulva, hymen, vagina and cervix [11]. Previous quadrivalent $\mathrm{HPV}$ vaccination was also assessed.

\section{Determination of HPV, CT and NG infections}

All exams were carried out in patients and healthy controls and were blinded to JIA disease parameters. HPV DNA testing was performed using Hybrid Capture 2 (HC2 high-risk; Digene Corporation, Gaithersburg, MD, USA) by DNA of oncogenic group of probes. These probes were chosen to detect 13 high-risk types of HPV $(16,18,31,33,35,39,45,51,52,56,58,59$ and 68). CT DNA testing and NG testing were performed using Hybrid Capture 2 (HC2 CT-ID DNA; Digene Corporation,
Gaithersburg, MD, USA). These HPV, CT and NG tests were performed following strictly the manufacturer's instructions and the results were presented as the ratio of the relative light units, which was considered positive when a relative light unit was greater than 1.0.

\section{Cervical cytology and histological evaluations}

The Pap smears were collected from virgin adolescents with Cytobrush ${ }^{\circ}$, the brush was inserted in the band of vaginal ostium and gently rotated $90^{\circ}$ to $180^{\circ}$, and immediately rolled over the slide. In sexually active patients, the cervicovaginal cytology was collected with Cytobrush $^{\circ}$ and spatula Ayre, after insertion of the speculum [11]. The cervix was visualized and the spatula Ayre was inserted in the ostium and rotated $360^{\circ}$ under gentle pressure, after inserting the Cytobrush ${ }^{\circ}$ for two thirds in the endocervical canal and rotated $90^{\circ}$ to $180^{\circ}$. The material of the Cytobrush ${ }^{\circ}$ was rolled over the slide and the material on the spatula Ayre was spread on a thin layer in one movement over the middle third of the slide. After the fixation by immersion in 95\% ethanol, the specimens were immediately transported to the laboratory [6]. All Pap smears were evaluated by the same cytopathologist blinded to gynecology examination in our University Hospital. They were performed according to the Bethesda Classification System in: 1) negative for intraepithelial lesions of malignancy with or without organisms (Trichomonas vaginalis, Candida spp, bacterial vaginosis, Actinomyces spp, herpes simplex virus), 2) other nonneoplastic findings (including inflammatory changes) and 3) epithelial cell abnormalities atypical [atypical squamous cells of undetermined significance (ASCUS), low-grade squamous intraepithelial lesion (LSIL) encompassing HPV/ mild dysplasia/cervical intraepithelial neoplasia (CIN) 1, high-grade squamous intraepithelial lesion (HSIL) encompassing moderate and severe dysplasia, carcinoma in situ, CIN 1 and CIN 2] [12]. Colposcopically guided biopsies were obtained of the most severe visible lesions. Specimen slides were reviewed by a pathologist who had no knowledge of the other clinical or laboratorial data [13].

\section{Clinical and laboratorial parameters}

The following JIA parameters were systematically assessed: number of active and limited joints, patient and physician global assessment of arthritis activity measured in a $10 \mathrm{~cm}$ horizontal visual analogy scale (VAS), erythrocyte sedimentation rate (ESR) by modified Westergren and $\mathrm{C}$-reactive protein (CPR) by nephelometric method.

\section{Current and previous treatment}

Use of non-steroidal anti-inflammatory drugs, corticosteroids, disease-modifying antirheumatic drugs DMARDs (methotrexate, leflunomide, sulfasalazine and hydroxichloroquine) and biological agents (etanercept, 
Table 1 Treatments in juvenile idiopathic arthritis (JIA) patients with abnormal and normal cervical cytology

\begin{tabular}{llll}
\hline Variables & Abnormal cervical cytology $(n=8)$ & Normal cervical cytology $(n=25)$ & \\
\hline Treatment & & & \\
Prednisone, current use & $2(25)$ & $5(16)$ & 0.616 \\
Current dose, mg/day & $6.3(5-7.5)$ & $10(0-61.2)$ & 0.800 \\
Cumulative dose, grams & $2(0-137.7)$ & $11(44)$ & 0.785 \\
Methotrexate, current use & $1(12)$ & $20(10-25)$ & 0.206 \\
Current dose, mg/week & $15(15-15)$ & $6.3(0.3-20.5)$ & $16(64)$ \\
Cumulative dose, grams & $1.7(0-16.7)$ & $6(24)$ & 0.383 \\
Biologic agents, current or previous use & $3(37)$ & $2(8)$ & 0.034 \\
Etanercept & $1(12)$ & $1(4)$ & 0.238 \\
Adalimumab & $0(0)$ & $1(4)$ & 0.652 \\
Golimumab & $0(0)$ & $0(0)$ & 1.000 \\
Certolizumab & $0(0)$ & $4(16)$ & 1.000 \\
Infliximab & $1(12)$ & $2(8)$ & 1.000 \\
Tocilizumab & $1(12)$ & 0.242 \\
Abatacept & $0(0)$ & 1.000
\end{tabular}

Values expressed as $\mathrm{n}(\%)$ or median (minimum - maximum value)

adalimumab, abatacept and tocilizumab) were systematically assessed.

\section{Statistical analysis}

The results for the continuous variables were presented by median (minimum and maximum values) or mean \pm standard deviation $(\mathrm{SD})$, and for categorical variables presented as frequency (percentage). The scores that had normal and abnormal distributions were compared by Student's t-test and Mann-Whitney test, respectively. The differences of categorical variables were calculated by Fisher's exact test. The adopted significance level in all analyses was set at 5\%.

\section{Results}

The mean current age was similar in JIA patients and healthy controls $(23.3 \pm 6.24$ vs. $26.1 \pm 6.03$ years, $p=$ 0.09). No differences in Caucasians and in upper middle and lower middle socio-economic classes were observed in both groups $(p>0.05)$. The mean of JIA duration was $15.0 \pm 7.3$ years (Table 2).

The frequencies of sexual intercourses $(76 \%$ vs. $89 \%$, $p=0.201)$, vaginal discharge $(30 \%$ vs. $18 \%, p=0.378)$ and abnormal cervical cytology $(24 \%$ vs. $11 \%, p=0.201)$ were similar in JIA patients compared to healthy controls. No differences were evidenced in sexual intercourse and sexual partner in both groups (Table 2). Group sex was not reported by any JIA patients and healthy controls.

According to hybrid capture detections, CT ( $0 \%$ vs. $7 \%, p=0.207)$ and NG infections ( $0 \%$ vs. $4 \%, p=0.459)$ were also similar in JIA patients and healthy controls. The frequency of HPV infection was higher in JIA patients than in controls, however without statistical significance ( $30 \%$ vs. $11 \%, p=0.155)$. Previous quadrivalent HPV vaccination was similar in both groups (6\% vs. $21 \%, p=0.127$ ) (Table 2). None of them had condylomata acuminata.

Further evaluation of JIA patients with abnormal and normal cervical cytology showed that the former group had a higher frequency of HPV infection $(87 \%$ vs. $12 \%$, $p=0.0002$ ). No differences were evidenced between two groups regarding demographic data, gynecologic history, sexual function, previous quadrivalent HPV vaccination and JIA clinical and laboratorial parameters $(p>0.05$; Table 3). The frequencies of current methotrexate $(12 \%$ vs. $44 \%, p=0.206)$ and biological agent use (37\% vs. $64 \%, p=0.238$ ) were similar in JIA patients with abnormal and normal cervical cytology.

\section{Discussion}

To our knowledge, this was the first study to assess lower genital infections in JIA patients allowing the identification of HPV as main cause of cervical dysplasia in this disease.

The strength of the present study was the systematic assessment of HPV, CT and NG infections in JIA patients and healthy controls with comparable age and sexual function. The use of hybrid capture test for HPV including the oncogenic group of probes is an additional advantage due to its high sensitivity and specificity $[13,14]$.

HPV infection identified in young JIA patients was subclinical, mild and significantly associated with cervical abnormalities and no evidence of cervical cancer. Contrasting with the reported increased risk of cervical dysplasia and persistent HPV infection in adults with RA 
Table 2 Demographic data, sexual function, gynecological evaluation, Pap smears, genital infections and HPV vaccination in juvenile idiopathic arthritis (JIA) patients and healthy controls

\begin{tabular}{|c|c|c|c|}
\hline Variables & $\mathrm{JIA}(n=33)$ & Controls $(n=28)$ & $p$ \\
\hline \multicolumn{4}{|l|}{ Demographic data } \\
\hline Current age, years & $23.3 \pm 6.24$ & $26.1 \pm 6.03$ & 0.090 \\
\hline Disease duration, years & $15 \pm 7.3$ & - & - \\
\hline Caucasian & $20(61)$ & $23(82)$ & 0.092 \\
\hline Upper-middle and lower-middle SE classes & $32(97)$ & $23(79)$ & 0.085 \\
\hline \multicolumn{4}{|l|}{ Sexual function and gynecological evaluation } \\
\hline Vaginal discharge & $10(30)$ & $5(18)$ & 0.378 \\
\hline Sexual intercourse & $25(76)$ & $25(89)$ & 0.201 \\
\hline First sexual activity age, years & $18(14-30)$ & $17(10-24)$ & 0.196 \\
\hline Sexual intercourse in last month & $19(57)$ & $19(68)$ & 0.439 \\
\hline Sexual intercourse in last month, number & $2(0-15)$ & $4(0-30)$ & 0.231 \\
\hline Sexual intercourse in last year & $23(70)$ & $21(75)$ & 0.767 \\
\hline Sexual intercourse in last year, number & $20(0-180)$ & $48(0-360)$ & 0.167 \\
\hline Sexual partner in last month, number & $1(0-1)$ & $1(0-2)$ & 0.148 \\
\hline Sexual partner in last year, number & $1(0-2)$ & $1(0-5)$ & 0.184 \\
\hline \multicolumn{4}{|l|}{ Pap smears and genital infections } \\
\hline Abnormal cervical cytology & $8(24)$ & $3(11)$ & 0.201 \\
\hline Inflammation & $25(76)$ & $25(89)$ & 0.201 \\
\hline ASCUS & $3(9)$ & $0(0)$ & 0.243 \\
\hline LSIL & $5(15)$ & $3(11)$ & 0.715 \\
\hline HSIL & $0(0)$ & $0(0)$ & 1.000 \\
\hline Gardnerella vaginalis & $4(12)$ & $1(4)$ & 0.367 \\
\hline Candida sp. & $0(0)$ & $1(4)$ & 0.459 \\
\hline Trichomonas vaginallis & $0(0)$ & $0(0)$ & 1.000 \\
\hline \multicolumn{4}{|l|}{ Hybrid capture detection } \\
\hline Chlamydia trachomatis & $0(0)$ & $2(7)$ & 0.207 \\
\hline Neisseria gonorrhoeae & $0(0)$ & $1(4)$ & 0.459 \\
\hline Human papillomavirus (HPV) & $10(30)$ & $3(11)$ & 0.115 \\
\hline Previous quadrivalent HPV vaccination & $2(6)$ & $6(21)$ & 0.127 \\
\hline
\end{tabular}

Values expressed as $\mathrm{n}(\%)$, median (minimum - maximum value) or mean \pm standard deviation

SE socio-economic, ASCUS atypical squamous cells of undetermined significance, LSIL low-grade squamous intraepithelial lesion, HSIL high-grade squamous intraepithelial lesion

$[5,6,15]$ and anogenital warts due to condyloma acuminatum in young systemic lupus erythematosus patients $[11,16]$. In Sjögren syndrome, a disease with mean age of onset usually in the 4th to 5th decade, a very low prevalence of HPV infection was evidenced [17].

CT and NG infections are rare in sexually active Chilean adolescents and young adults [18] and adult RA patients [6]. Likewise, we have not observed these STI in JIA or health control groups.

A high rate of serious infections, including tuberculosis, herpes zoster and systemic mycosis, were reported in JIA patients under biologic therapy and methotrexate in a real-life setting [19]. On the contrary, anti-TNF does not seem to increase short-term risk of exacerbation and/or progression genital infections (HPV and CT) in RA patients [6]. Further prospective studies are necessary to determine if JIA patients with HPV will develop cervical cancer, and therefore a rigorous surveillance is recommended for this group of patients.

Only $6 \%$ of our JIA patients received previous HPV vaccination, in spite of prompt indication by our service for all adolescent and young JIA patients. In fact, HPV vaccines are efficacious and safe in patients with autoimmune diseases, including systemic lupus 
Table 3 Demographic data, sexual function, gynecological evaluation, Pap smears, genital infections and HPV vaccination and disease parameters in juvenile idiopathic arthritis (JIA) patients with abnormal and normal cervical cytology

\begin{tabular}{|c|c|c|c|}
\hline Variables & Abnormal cervical cytology $(n=8)$ & Normal cervical cytology $(n=25)$ & $p$ \\
\hline \multicolumn{4}{|l|}{ Demographic data } \\
\hline Current age, years & $26.2 \pm 6.3$ & $23.5 \pm 6.3$ & 0.730 \\
\hline Disease duration, years & $13.5 \pm 6.6$ & $15.9 \pm 7.5$ & 0.427 \\
\hline Caucasian & $4(50)$ & $16(64)$ & 0.681 \\
\hline Upper middle and lower middle SE class & $8(100)$ & $24(96)$ & 1.000 \\
\hline \multicolumn{4}{|l|}{ Sexual function and gynecological evaluation } \\
\hline Vaginal discharge & $4(50)$ & $6(24)$ & 0.205 \\
\hline Sexual activity & $7(87)$ & $18(72)$ & 0.649 \\
\hline First sexual activity age, years & $19.5(15-22)$ & $17(14-30)$ & 0.779 \\
\hline Sexual intercourse in last month & $4(50)$ & $15(60)$ & 0.695 \\
\hline Sexual intercourse in last month, number & $1(0-12)$ & $2.5(0-15)$ & 0.85 \\
\hline Sexual intercourse in last year & $6(75)$ & $17(68)$ & 1.000 \\
\hline Sexual intercourse in last year, number & $12(0-144)$ & $20(0-180)$ & 0.813 \\
\hline Sexual partner in last month, number & $1(0-1)$ & $1(0-1)$ & 0.849 \\
\hline Sexual partner in last year, number & $1(0-1)$ & $1(0-2)$ & 0.776 \\
\hline \multicolumn{4}{|l|}{ Urogenital infections } \\
\hline Gardnerella vaginalis & $1(12)$ & $3(12)$ & 1.000 \\
\hline Candida sp. & $0(0)$ & $0(0)$ & 1.000 \\
\hline Trichomonas vaginallis & $0(0)$ & $0(0)$ & 1.000 \\
\hline \multicolumn{4}{|l|}{ Hybrid capture detection } \\
\hline Chlamydia trachomatis & $0(0)$ & $0(0)$ & 1.000 \\
\hline Neisseria gonorrhoeae & $0(0)$ & $0(0)$ & 1.000 \\
\hline Human Papillomavirus (HPV) & $7(87)$ & $3(12)$ & 0.0002 \\
\hline Previous quadrivalent HPV vaccination & $0(0)$ & $2(8)$ & 1.000 \\
\hline \multicolumn{4}{|l|}{ JIA clinical and laboratory parameters } \\
\hline JADAS 71 (0-101) & 0 & $2(0-5)$ & NA \\
\hline DAS28 (0-7) & $4.5(1.36-2.66)$ & $5.0(1.05-5.21)$ & 0.674 \\
\hline Number of active joints & $0(0-3)$ & $1(0-12)$ & 0.514 \\
\hline Number of limited joints & $1.5(0-43)$ & $5(0-39)$ & 0.425 \\
\hline Patient global VAS (0-10) & $1.5(0-8)$ & $2(0-9)$ & 0.705 \\
\hline Physician global VAS (0-10) & $0(0-2)$ & $1(0-5)$ & 0.344 \\
\hline ESR, mm/1st hour & $12.8 \pm 5.4$ & $9.7 \pm 6.9$ & 0.268 \\
\hline CRP, mg/L & $3.7(0.4-77)$ & $1.8(0.2-14)$ & 0.257 \\
\hline
\end{tabular}

Values expressed as $\mathrm{n}(\%)$, median (minimum - maximum value) or mean \pm standard deviation

SE socio-economic, JADAS71 Juvenile Arthritis Disease Activity Score, DAS28 Disease Activity Score 28-Joint Counts, NA not applicable, VAS visual analog scale, CRP C-reactive protein (normal range method: $<5 \mathrm{mg} / \mathrm{L}$ ), ESR erythrocyte sedimentation rate

erythematosus and JIA, and systematic use should be reinforced for all patients in clinical practice $[20,21]$.

In addition, methotrexate and biological agents do not seem to increase the risk of lower genital tract infections in JIA patients.

\section{Conclusions}

This study further reinforces the importance of vaccination in adolescent with chronic arthritis. It also showed a low frequency of STIs in spite of immunosuppressive and biological agents exposure. We further demonstrated that cervical dysplasia in JIA patients was highly associated with HPV, reinforcing the need of close observation and HPV immunization during childhood.

\section{Abbreviations}

ASCUS: Atypical squamous cells of undetermined significance; CIN: Cervical intraepithelial neoplasia; CPR: C-reactive protein; CT: Chlamydia trachomatis: DMARDs: Disease-modifying antirheumatic drugs; DNA: Deoxyribonucleic 
acid; ESR: Erythrocyte sedimentation rate; HPV: Human papillomavirus; HSIL: High-grade squamous intraepithelial lesion; ILAR: International League of Associations for Rheumatology; JIA: Juvenile idiopathic arthritis; LSIL: Lowgrade squamous intraepithelial lesion; NG: Neisseria gonorrhoeae; RA: Rheumatoid arthritis; SD: Standard deviation; STI: Sexually transmitted infections; VAS: Visual analogy scale

\section{Acknowledgements}

Not applicable.

\section{Authors' contributions}

All authors analyzed and interpreted the patient data. GVRF, RBT, EB and CAS were the major contributor in writing the manuscript. All authors read and approved the final manuscript.

\section{Funding}

This study was supported by grants from Conselho Nacional de Desenvolvimento Científico e Tecnológico (CNPq 301805/2013-0 to RMRP, 305068/2014-8 to EB and 303422/2015-7 to CAS), Fundação de Amparo à Pesquisa do Estado de São Paulo (FAPESP 2014/14806-0 to CAS; 2015/037564 to CAS), Federico Foundation (to RMRP, EB and CAS) and by Núcleo de Apoio à Pesquisa "Saúde da Criança e do Adolescente" da USP (NAP-CriAd) to CAS.

\section{Availability of data and materials \\ Not applicable.}

\section{Ethics approval and consent to participate}

This study was approved by our Ethics Committee. The Local Ethics Committee of our tertiary service (CAPPesq - Comissão de Pesquisa e Ética do Hospital das Clínicas da Faculdade de Medicina da Universidade de São Paulo) approved the study and an informed consent was obtained from all participants or their legal guardian. The Local Ethics Committee of our tertiary service (CAPPesq - Comissão de Pesquisa e Ética do Hospital das Clínicas da Faculdade de Medicina da Universidade de São Paulo) approved the study and an informed consent was obtained from all participants or their legal guardian.

\section{Consent for publication}

All JIA patients and healthy controls signed the consent for publication.

\section{Competing interests}

The authors declare that they have no competing interests.

\section{Author details}

${ }^{1}$ Pediatric Rheumatology Unit, Children's Institute, Hospital das Clinicas HCFMUSP, Faculdade de Medicina, Universidade de Sao Paulo, Av. Dr. Eneas Carvalho Aguiar, 647 - Cerqueira César, São Paulo, SP 05403-000, Brazil. ${ }^{2}$ Discipline of Gynecology, Hospital das Clinicas HCFMUSP, Faculdade de Medicina, Universidade de Sao Paulo, São Paulo, SP, Brazil. 'Rheumatology Division, Hospital das Clinicas HCFMUSP, Faculdade de Medicina, Universidade de Sao Paulo, Av. Dr. Eneas Carvalho Aguiar, 647 - Cerqueira César, São Paulo, SP 05403-000, Brazil. ${ }^{4}$ Adolescent Unit, Children's Institute, Hospital das Clinicas HCFMUSP, Faculdade de Medicina, Universidade de Sao Paulo, São Paulo, SP, Brazil.

Received: 1 August 2019 Accepted: 24 October 2019

Published online: 15 November 2019

\section{References}

1. Prakken B, Albani S, Martini A. Juvenile idiopathic arthritis. Lancet. 2011;377: 2138-49.

2. Pugliese C, van der Vinne RT, Campos LM, Guardieiro PR, Saviolli C, Bonfa E. Juvenile idiopathic arthritis activity and function ability: deleterious effects in periodontal disease? Clin Rheumatol. 2016;35:81-91.

3. Gualano B, Bonfa E, Pereira RM, Silva CA. Physical activity for paediatric rheumatic diseases: standing up against old paradigms. Nat Rev Rheumatol. 2017:13:368-79.

4. van Weelden M, Lourenço B, Viola GR, Aikawa NE, Queiroz LB, Silva CA. Substance use and sexual function in juvenile idiopathic arthritis. Rev Bras Reumatol. 2016;56:323-9.
5. Rojo-Contreras W, Olivas-Flores EM, Gamez-Nava Jl, et al. Cervical human papillomavirus infection in Mexican women with systemic lupus erythematosus or rheumatoid arthritis. Lupus. 2012;21:365-72.

6. Waisberg MG, Ribeiro AC, Candido WM, et al. Human papillomavirus and chlamydia trachomatis infections in rheumatoid arthritis under anti-TNF therapy: an observational study. Rheumatol Int. 2015;35:459-63.

7. Yu X, Zheng H. Refractory genital HPV infection and adult-onset still disease: a case report and literature review. Medicine (Baltimore). 2016;95:e3169.

8. Cordtz R, Mellemkjær L, Glintborg B, et al. Risk of virus-associated cancer in female arthritis patients treated with biological DMARDs-a cohort study. Rheumatology (Oxford). 2016:55:1017-22.

9. Petty RE, Southwood TR, Manners P, et al. International league of associations for rheumatology classification of juvenile idiopathic arthritis: second revision, Edmonton, 2001. J Rheumatol. 2004;31:390-2.

10. Critério de Classificação Econômica Brasil. ABEP (Associação Brasileira de Empresas de Pesquisa); 2014. p. 1-5.

11. Febrônio MV, Pereira RMR, Bonfá E, Takiuti AD, Pereyra EAG, Silva CAA Inflammatory cervicovaginal cytology is associated with disease activity in juvenile systemic lupus erythematosus. Lupus. 2007;16:430-5.

12. Solomon D, Davey D, Kurman R, et al. The 2001 Bethesda system: terminology for reporting results of cervical cytology. JAMA. 2002;287:2114-9.

13. Beldi MC, Tacla M, Caiaffa-Filho H, et al. Implementing human papillomavirus testing in a public health hospital: challenges and opportunities. Acta Cytol. 2012;56:160-5.

14. Luu HN, Dahlstrom KR, Mullen PD, VonVille HM, Scheurer ME. Comparison of the accuracy of hybrid capture $\|$ and polymerase chain reaction in detecting clinically important cervical dysplasia: a systematic review and meta-analysis. Cancer Med. 2013;2:367-90.

15. Raposo A, Tani C, Costa J, Mosca M. Human papillomavirus infection and cervical lesions in rheumatic diseases: a systematic review. Acta Reumatol Port. 2016:41:184-90.

16. Lube G, Aikawa NE, Tacla M, et al. Condyloma acuminatum by human papilloma virus infection in childhood-systemic lupus erythematosus patients. Acta Reumatol Port. 2014;39:182-7.

17. Cirpan T, Guliyeva A, Onder G, et al. Comparison of human papillomavirus testing and cervical cytology with colposcopic examination and biopsy in cervical cancer screening in a cohort of patients with Sjogren's syndrome. Eur J Gynaecol Oncol. 2007;28:302-6.

18. Huneeus A, Schilling A, Fernandez Ml. Prevalence of chlamydia trachomatis, Neisseria gonorrhoeae, and Trichomonas vaginalis infection in Chilean adolescents and young adults. J Pediatr Adolesc Gynecol. 2018;51083: 30011-21.

19. Brunelli JB, Schmidt AR, Sallum AM. High rate of serious infection in juvenile idiopathic arthritis patients under biologic therapy in a real-life setting. Mod Rheumatol. 2018;28:264-70.

20. Pellegrino P, Radice S, Clementi E. Immunogenicity and safety of the human papillomavirus vaccine in patients with autoimmune diseases: a systematic review. Vaccine. 2015:33:3444-9.

21. Heijstek MW, Scherpenisse M, Groot N, et al. Immunogenicity and safety of the bivalent HPV vaccine in female patients with juvenile idiopathic arthritis: a prospective controlled observational cohort study. Ann Rheum Dis. 2014; 73:1500-7.

\section{Publisher's Note}

Springer Nature remains neutral with regard to jurisdictional claims in published maps and institutional affiliations.

Ready to submit your research? Choose BMC and benefit from:

- fast, convenient online submission

- thorough peer review by experienced researchers in your field

- rapid publication on acceptance

- support for research data, including large and complex data types

- gold Open Access which fosters wider collaboration and increased citations

- maximum visibility for your research: over $100 \mathrm{M}$ website views per year

At BMC, research is always in progress.

Learn more biomedcentral.com/submissions 